\title{
POÉTICAS E POLÍTICAS DE TRANSFORMAÇÃO DO MUNDO SOCIAL: MIGRAÇÕES RECENTES DE HAITIANOS E SENEGALESES NA REGIÃO DA GRANDE FLORIANÓPOLIS (SC)
}

\author{
TRANSFORMATION POETICS AND POLITICS OF THE SOCIAL WORLD: \\ RECENT MIGRATION OF HAITIANS AND SENEGALESE IN THE GREATER \\ FLORIANÓPOLIS REGION (SC)
}

Janaina Santos Macedo ${ }^{1}$

doi) $10.21665 / 2318-3888 . v 5 n 10 p 180-203$

\section{RESUMO}

O presente artigo pretende propor uma reflexão acerca das migrações recentes como possibilidades poéticas e políticas de transformação do mundo social. O fenômeno migratório deste século XXI, a partir de uma pesquisa antropológica situada na região da Grande Florianópolis, em Santa Catarina, é analisado através de seus atravessamentos e possibilidades de desencadear e suscitar transformações. O enfoque proposto, para além das precariedades e restrições de acesso a direitos que incidem sobre populações migrantes no contexto local, atenta para a positividade do processo migratório. Através desta perspectiva, construída a partir do trabalho etnográfico realizado junto a migrantes provenientes do Haiti e do Senegal, tornou-se possível compreender os constantes deslocamentos e reelaborações de identidades e de modos de estar no mundo destes sujeitos como mais fluídos e menos estáveis. As experiências cotidianas destes novos fluxos migratórios, deste modo, são tomadas como desencadeadoras de novos paradigmas de relações contra hegemônicas. As migrações assumem, sob este viés, uma dimensão política e poética performada e experienciada cotidianamente, que se expande através dos fluxos e movimentos, criando efeitos transformadores transnacionalmente. Assim, as populações migrantes desencadeiam, através de seus múltiplos deslocamentos, movimentos de transformação social, performando novas possibilidades éticas de resistências à ordem e às fronteiras estabelecidas e, que através de uma perspectiva que parte da universalidade do acesso aos direitos humanos, aponta

1 Doutoranda em Antropologia Social no PPGAS/UFSC, Mestre em História Cultural. Especialista em Educação a Distância, membro do GAIRF (Grupo de Apoio a Imigrantes e Refugiados de Florianópolis e região), do GT I (Grupo de Trabalho sobre Imigração da Comissão de Direitos Humanos da ALESC) e do Observatório das Migrações da UDESC. Vinculada ao GESTO (Grupo de Estudos em Oralidade e Performance). E-mail: janaina.santos@ufsc.br 
para a criação e o desenvolvimento de uma ética de coabitação. Esperamos contribuir para iluminar positivamente os estudos sobre processos migratórios e, desta maneira, seguir o exemplo proposto pelos sujeitos migrantes de transformar a realidade social.

Palavras-chave: Migração. Transformação Social. Liminaridades. Montagens. Antropologia. 


\section{ABSTRACT}

The present article intends to propose a reflection about the recent migrations as poetic and politics possibilities of transformation of the social world. The migratory phenomenon of this XXI century, based on an anthropological research located in Santa Catarina, is analyzed for its limitations, assemblies and possibilities of unchaining and provoking transformations. The proposed approach, in addition to the precariousness and restrictions of access to rights that affect migrant populations in the local context, attentive to the positivity of the migration process. Through this perspective, built on the ethnographic work carried out with immigrants and refugees from Haiti and Senegal, it became possible to understand in a different way the constant displacements and reelaborations of identities and ways of being in the world of these subjects, perceived as more fluid and less stable. The daily experiences of these new migratory flows, in this way, are taken as triggering new paradigms of counter-hegemonic relations. Migrations - both voluntary and involuntary (refuge situation) - assume a political and poetic dimension performed and experienced on a daily basis, which expands through flows and movements, creating transformational effects transnationally. Thus, migrant populations unleash movements of social transformation through their multiple displacements, performing new ethical possibilities of resistance to order and established boundaries and, through a perspective that starts from the universality of access to human rights, points to the Creation and development of a cohabitation ethic. We hope to contribute to a positive illumination of the studies of migratory processes and, in this way, to follow the example proposed by the migrant subjects of transforming the social reality.

Keywords: Migration. Social Transformation. Liminarities. Montages. Anthropology. 


\section{Introdução}

O presente artigo propõe uma reflexão acerca do fenômeno global das migrações recentes como possibilidades (co)movedoras poética e politicamente de transformação do mundo social. Deste modo os deslocamentos populacionais deste início do século XXI, a partir do contexto local do Estado de Santa Catarina, são analisados a partir de seus atravessamentos e interseccionalidades através das narrativas e performances de migrantes haitianos e senegaleses. O enfoque proposto, para além das precariedades e restrições de acesso a direitos que incidem sobre populações migrantes, aponta para positividade das migrações. Através desta perspectiva, os constantes deslocamentos e reelaborações identitárias e de modos de estar no mundo, mais fluídos e menos estáveis destes novos fluxos migratórios podem ser compreendidos como desencadeadores de novos paradigmas epistemológicos de relações contra hegemônicas. As migrações assumem, sob este viés, uma dimensão política e poética performada e experienciada cotidianamente, que se expande através dos fluxos e movimentos, criando efeitos transformadores transnacionalmente. Assim, as populações migrantes desencadeiam, através de seus múltiplos deslocamentos, movimentos de transformação social, estabelecendo novas possibilidades éticas de resistências à ordem e às fronteiras estabelecidas.

Pretendemos iluminar o processo migratório sob um viés poético e também político, apresentar um breve panorama sobre as migrações deste início do século XXI e situar nossos interlocutores locais. Situamos alguns dos múltiplos sentidos evocados e criados pelos processos migratórios, ampliando a perspectiva para além das precariedades e disjunções. Na sequência delineamos alguns efeitos e disrupções criados ou performados pelos trânsitos de pessoas e concluímos, esperando demonstrar o quanto estes sujeitos migrantes podem contribuir para descentrar nossas relações historicamente assimétricas e desiguais, provocando uma reestruturação que possa ser 'boa para pensar' e, quem sabe, que nos torne mais capazes de sustentar uma ética de coabitação (BUTLER, 2017a). 


\section{Um olhar sobre o potencial poético e político dos processos migratórios}

A ideia de uma poética dos processos migratórios foi inspirada em Sansot (1986) visando evitar significações unívocas sobre os sujeitos e seus fluxos, privilegiando o foco nas múltiplas possibilidades e nos significados criados, evocados, transformados, performados e exigidos por seus deslocamentos e presenças. Assim os processos migratórios humanos, para além dos trânsitos de pessoas, práticas, afetos, informações e saberes, nos fazem refletir sobre fixidez, fronteiras, permeabilidade e transformações dentro de um fluxo constante de movimento.

Esta abordagem das migrações como possibilidades poéticas e políticas de transformação do social foi inicialmente pensada a partir de leitura de $O$ espelho da Tauromaquia, de Michel Leiris (2001). Narrando diversas imagens evocadas a partir da tauromaquia, o autor menciona a importância dos 'construtores de espelhos', aqueles que ao invés de banir ou mascarar a morte, incorporam-na à vida, com todos os riscos envolvidos e assim, ao olharem a morte de frente, mergulham no abismo e de lá saem, num processo de transmutação. Fruto de uma revelação, no sentido de uma experiência crucial, a tauromaquia vista através do espelho esclarece aspectos obscuros da vida, aquilo que não tem uma forma única, mas que é repleto de ambivalências e polissemias. Segundo Leiris,

(...) certos lugares, certos acontecimentos, certos objetos, certas circunstâncias muito raros suscitam, quando sobrevém que se apresentem ou que nos envolvamos com eles, a sensação de que sua função na ordem geral das coisas consiste em nos pôr em contato com o que há em cada qual de mais profundamente íntimo, de mais quotidianamente turvo e mesmo de mais impenetravelmente oculto (LEIRIS, 2001, p.11).

Neste sentido a tauromaquia, bem como a arte, teria lugar na interação de contrastes, no paroxismo, no escancaramento de ambiguidades, dissonâncias, passagens liminares e, portanto, transformadoras. Segundo ele os construtores de espelhos seriam os toureiros, os poetas e os amantes que nos proporcionam revelações a partir de experiências cruciais, lançando luz sobre nós mesmos e visibilizando contradições e contrastes, como no jogo/dança/luta/relação entre o touro e o toureiro. No limiar entre a vida e a morte, entre o sagrado e profano, na fronteira entre o 'reto' e o 'torto' acontece um movimento de aproximação e afastamento da morte e um (re)nascimento torna-se 
possível, sob a iminência e a presença dos riscos. Sua função a partir dos "lugares em que o homem tangencia o mundo e a si mesmo" (idem, p.75) seria incorporar a morte a vida, lembrando que o mundo vai além do que é visível, objetivo, fixo e estável.

Nossa proposta aqui é considerar os migrantes também como construtores de espelhos, na medida em que nos obrigam a olhar para outras realidades, assim como para nós mesmos e refletir sobre as construções sociais que tornaram possível nossa atual configuração social com suas hegemonias e fronteiras.

A perspectiva processual permite perceber o fenômeno dos deslocamentos humanos contemporâneos, em especial no que se relaciona à região da Grande Florianópolis (SC) e aos grupos de imigrantes que por aqui têm se estabelecido ou circulado como parte dos fluxos globais, de acordo com Anna Tsing (2000), numa abordagem que atenta às interconexões mas que evita a homogeneização. Assim as constantes mudanças de (etno)paisagens envolvem e transformam práticas, narrativas e performatividades de indivíduos e grupos de indivíduos com múltiplos pertencimentos, implicando constantes reconfigurações poéticas e políticas. E assim, ao reconfigurarem a si e aos seus próprios movimentos, transformam o mundo social, impulsionando transformações, no sentido de '(co)mover'. Esta expressão enfatiza a "experiência física do movimento entre lugares" (Thomson, 2002, p. 359) e simultaneamente evoca afetos, através dos sentidos do mover e do comover. Isto se deve ao fato de que os planos e trajetórias dos sujeitos migrantes são, em geral, continuamente reelaborados, assim como os sentidos implicados nos processos migratórios e nas narrativas e performances que os acompanham, permanecendo em constante movimento ou movimentando-se com relativa facilidade, apesar das fronteiras reais e simbólicas.

O sentido de performativo, desenvolvido por Butler, evoca uma discursividade enquanto capacidade dos atores sociais de constituírem seus mundos, enfatizando o potencial mobilizador e continuamente transformativo de pertencimentos e identidades. "A performatividade deve ser entendida", diz Butler, "não como um 'ato' singular e deliberado, senão antes como a prática reiterativa e referencial mediante a qual o discurso produz os efeitos que nomeia" (BUTLER, 2002, p.18). Sob esta perspectiva o 
performativo rompe com a fixidez e a imobilidade dos sentidos e aponta para uma dimensão revolucionária. "Quando se fala de performatividade é para referir aos enunciados linguísticos que, no momento em que são pronunciados, criam uma realidade ou fazem que exista algo pelo simples fato de tê-lo expressado" (BUTLER, 2017a, p. 34, tradução livre).

De Certeau também demonstra como através de relatos ou narrativas é possível atravessar e organizar o espaço, sendo o próprio relato "uma prática do espaço" (DE CERTEAU: 2014, p. 183). As narrativas, consideradas como elaborações construídas a partir dos processos migratórios, compreendem práticas reflexivas e organizadoras das experiências e dos múltiplos movimentos. Esta ênfase na subjetividade a partir da experiência, não apenas de grupos mas também de sujeitos, embora ambos estejam em relação, faz com que os relatos sejam transformadores de espaços, lugares e relações. Mais do que descrever e fixar, os relatos são criadores com "poder distributivo e força performativa" (idem, p. 191)", estabelecendo dinâmicas complexas de diferenciação que são continuamente atualizadas, assim como as fronteiras são ultrapassadas no próprio relato para se transformarem em pontes. Desta forma o que antes separava transformase em conector.

Entretanto, o fenômeno migratório, como já dito, apresenta diversas interseccionalidades. Entre elas raça, gênero e religião podem atuar como facilitadores para alguns grupos ou indivíduos e ao mesmo tempo impor sucessivas fronteiras a outros. Através da pesquisa de campo com migrantes haitianos e senegaleses tornou-se imperativo perceber que o fenômeno migratório e a receptividade dos indivíduos pelos diferentes Estados-nação varia conforme os sistemas raciais construídos, que segundo Vilna Bashi (2004), classificam pessoas, seja através do fenótipo ou de características relacionadas principalmente à cor da pele ou pertencimentos étnicos ou religiosos, operando categorias hierarquizadas de imigrantes desejáveis ou indesejáveis.

Segundo esta autora, ainda que não mais discursivamente, pelas práticas históricas é possível falar de racismo nas políticas de imigração - assim como de refúgio - das nações ocidentais, e imigrantes brancos têm sido preferidos pelas nações ocidentais, ao passo 
que negros têm sido sistematicamente associados a ilegalidades, desordens, doenças e perigos. Bashi (2004) refere-se ao contexto canadense, mas a mesma realidade pode ser percebida em diversos países. Logo no início da República, depois de séculos de imigração forçada de populações escravizadas da África, o Decreto no 528, de 28 de Junho de 1890 que "Regularisa[va] o serviço da introducção e localisação de immigrantes na Republica dos Estados Unidos do Brazil" (sic) no seu artigo 1ํo afirmava: "É inteiramente livre a entrada, nos portos da Republica, dos indivíduos válidos e aptos para o trabalho, que não se acharem sujeitos á acção criminal do seu paiz, exceptuados os indigenas da Asia, ou da Africa que somente mediante autorização do Congresso Nacional poderão ser admittidos de accordo com as condições que forem então estipuladas" 2 (sic). Este decreto mostra-se extremamente racista e engajado na política de branqueamento do Brasil, procurando normatizar a seleção dos imigrantes pela cor da pele.

Tal decreto perdeu sua vigência legal no ano seguinte, devido aos interesses comerciais com China e Japão, mas a histórica segregação e preconceito dispensado às populações negras não recrudesceu, como podemos perceber pela análise dos discursos veiculados na imprensa local. Desta maneira os primeiros grupos de haitianos a chegarem ao Brasil a partir de 2010 foram arbitrariamente considerados grupos "invasores" e associados à cólera e outras doenças infectocontagiosas, como se pode ver pelas manchetes "Amazonas adota medida para impedir entrada do cólera com haitianos" 3 e "Suspeita de ebola acirra preconceito contra haitianos" ${ }^{\prime 4}$. Da mesma forma em relação aos senegaleses em Santa Catarina foi construída uma imagem de serem comerciantes ilegais que comercializariam mercadorias falsificadas e de serem cooptados por redes criminosas internacionais. Na verdade, estas atribuições constituem discursos de segregação e racismo midiático e institucional, por parte do poder público e privado em

2 http://www2.camara.leg.br/legin/fed/decret/1824-1899/decreto-528-28-junho-1890-506935publicacaooriginal-1-pe.html

3 Publicada no dia 08/02/2011 no G1. Disponível em: http://g1.globo.com/brasil/noticia/2011/02/amazonas-adota-medida-para-impedir-entrada-do-coleracom-haitianos.html

4 Publicada no dia 13/10/2014 no Jornal do Povo (PR). Disponível em: http://jornaldopovoparana.com/suspeita-de-ebola-acirra-preconceito-contra-haitianos/ 
suas diversas esferas e em nada representam as atividades desenvolvidas por esta população.

\section{Um olhar sobre o contexto local}

O mundo contemporâneo experimenta um momento em que constantes deslocamentos populacionais vêm transformando continuamente relações, escalas e paisagens sociais (APPADURAI, 2004). No Brasil, como no contexto catarinense, foi principalmente a partir de $2010^{5}$ com a entrada de grandes contingentes de imigrantes haitianos que se iniciou um processo de visibilização daquilo que muitas vezes é designado como 'crise migratória' (BAUMAN, 2016) mundial e que se recolocou na pauta a necessidade de revisão da política migratória nacional que de fato se concretizou em maio de 2017, quando foi instituída a nova Lei de Migração ${ }^{6}$. Desde 2010 ingressaram no Brasil mais de 90 mil imigrantes haitianos com o visto humanitário ${ }^{7}$. Entretanto este fluxo migratório de haitianos, até então praticamente inédito para o Brasil e que teve grande visibilidade através dos meios de comunicação não foi o único.

Também houve neste período o ingresso de importantes contingentes de senegaleses, equatorianos, bolivianos, ganeses, sírios, norte-americanos, espanhóis, portugueses, venezuelanos, dentre outros, pois a partir de 2008, o Brasil tornou-se novamente uma opção para diversos sujeitos em deslocamento. Essa virada de um país de emigração para um país de imigração ocorreu a partir de 2007 quando uma grande crise econômica global afetou Europa e os Estados Unidos, que passaram a restringir a entrada de novos fluxos migratórios, aliada aos grandes eventos esportivos ocorridos no Brasil em $2014^{8}$

\footnotetext{
${ }^{5} \mathrm{~A}$ entrada de haitianos no Brasil, antes pouco expressiva, torna-se visível após o terremoto de 12 de janeiro de 2010, mas a história de exploração, colonialismo e imperialismo vivida pelo país contribuiu para a criação da diáspora haitiana, realidade de mais de um século que foi muito bem resumida por Eduardo Galeano em seu artigo "La Maldicion Blanca", de 2004, quando do bicentenário de sua independência. Disponível em http://www.grupotortuga.com/Por-que-Haiti-es-tan-pobre-dos

${ }^{6}$ Lei № 13.445 , de 24 de maio de 2017.

7 De acordo com a resolução normativa no 97 do CNIg foi instituído o Visto Permanente por Razões Humanitárias aos imigrantes haitianos, uma vez que não se enquadravam na categoria de refugiados, conforme estabelecida pelo Comitê Nacional para os Refugiados (Conare) através da lei no 9.474/97 amparado no Estatuto dos Refugiados de 1951 e no Protocolo de 1967.

${ }^{8}$ Copa do Mundo de Futebol.
} 
e em $2016^{9}$, que prometiam multiplicar empregos e rendas. Além disso, no caso do Haiti, havia a presença militar brasileira naquele país desde 2004 através da Missão de Estabilização da Paz (Minustah), juntamente com outras organizações religiosas e não governamentais, como a Cáritas e a Viva Rio. No caso do Senegal, muitas imigrações foram estimuladas pela busca por mão-de-obra muçulmana por parte de empresas brasileiras exportadoras de produtos para certos países que exigiam procedimentos específicos na linha de produção, como o abate halal, embora a partir da etnografia outros motivos se revelem. Outro fator de atração da população destes dois países para o Brasil passa pelas representações de igualdade social e racial veiculadas em seus países através das novelas e do futebol brasileiros, que na maior parte das vezes são desmentidas pelo preconceito e racismo experimentados no Brasil.

Os deslocamentos recentes, portanto, apesar de constituírem um fenômeno já experimentado na formação do nosso Estado-nacional - considerando desde as migrações forçadas de populações escravizadas da África, como também as migrações europeias dos séculos XVIII, XIX e XX, destinadas a ocupar terras consideradas 'desocupadas' apesar da presença invisibilizada das populações indígenas, bem como de colaborar com o processo de branqueamento do Brasil - apresentam-se agora nesta segunda década do século XXI em nova intensidade. Neste processo estão relacionadas (re)construções identitárias e (des)reterritorializações constantes, assim como precariedades, conforme Sayad (1998) e Butler (2009).

A região da Grande Florianópolis, na qual a presente análise se debruça, é composta por 22 municípios e, segundo o Censo do IBGE de 2011, possui população superior a 1.027.271 habitantes, tendo como sede a capital de Santa Catarina. Refletimos sobre os processos migratórios e deslocamentos recentes para esta região, principalmente nas cidades de Florianópolis, São José, Palhoça e Santo Amaro da Imperatriz, que a partir de 2010 passaram a receber importantes contingentes de migrantes haitianos(as) e senegaleses(as), entre outros grupos de imigrantes e refugiados. A população haitiana na região, tendo chegado ao longo da segunda década do século XX, era inicialmente

\footnotetext{
${ }^{9}$ Olimpíadas e Paraolimpíadas.
} 
composta majoritariamente por homens, apesar de ser visível a feminização dos fluxos migratórios no mundo todo, inclusive aqui. De modo geral, as mulheres vinham em um segundo momento, quando o marido ou irmão já se encontravam estabelecidos.

Inicialmente os imigrantes chegavam à região isoladamente, mas a partir de maio de 2015, devido ao grande represamento no Acre, ônibus começaram a levar estes imigrantes para as capitais de alguns Estados, como foi o caso de Florianópolis, onde 18 ônibus chegaram em aproximadamente três meses. O primeiro deles, com 42 pessoas, contava com 17 imigrantes haitianos (sendo 14 homens e 3 mulheres) e 25 imigrantes senegaleses (todos homens) ${ }^{10}$. Pode-se dizer que esta tendência se manteve nos demais ônibus, com aumento gradual e constante do número de mulheres. Importante destacar que embora muitas tenham vindo dentro de um projeto de reunificação familiar ou contando com a rede de familiares já estabelecida aqui, a pesquisa etnográfica iluminou um outro aspecto desta experiência migratória.

No que tange à questão de gênero, desde o início foi possível perceber uma importante presença feminina em termos qualitativos, ainda que minoritária quantitativamente. Se numericamente predominavam os homens e a chegada das mulheres estava reservada a um segundo momento (BORDIGNON, 2016), a pesquisa de campo demonstra uma realidade menos homogênea. Em muitos casos, os maridos ficaram no país de origem enquanto as mulheres vieram, sozinhas ou com outras mulheres - filhas, enteadas, irmãs, amigas - para estabelecerem-se e depois trazê-los, como foi o caso de Marylin ${ }^{11}$, que deixou a filha ainda bebê aos cuidados do marido no Haiti, conseguindo trazê-los após três anos, muito trabalho e muitas horas extras, e de Marianne ${ }^{12}$, que veio sozinha do Senegal, deixando lá seu marido que a seguiu cerca de um ano depois. Isto também aconteceu com moças jovens e solteiras que foram escolhidas por suas famílias para virem trabalhar e estudar, como aconteceu com Ema e Fabielle ${ }^{13}$, ambas haitianas,

\footnotetext{
10 Dados obtidos em campo, junto à Secretaria de Assistência Social do Estado de Santa Catarina.

11 Este, assim como todos os demais nomes de meus interlocutores e minhas interlocutoras são fictícios para preservar suas identidades.

12 Marianne era e é responsável pelo sustento de oito pessoas no Senegal.

13 Ambas são responsáveis por enviar dinheiro para as famílias no Haiti, que compreendem oito e sete pessoas respectivamente.
} 
incumbidas de ajudar as famílias. Nestes, assim como nos outros casos, os familiares que ficaram nos países de origem dependiam e ainda dependem das remessas enviadas mensalmente para seu sustento.

As populações migrantes são determinantes para o sustento de famílias e países transnacionalmente e no caso do Haiti e do Senegal o papel da diáspora é fundamental no desenvolvimento econômico do país de origem. O Senegal é considerado a $12^{\mathrm{a}}$ economia do oeste da África e o número de emigrantes varia entre 500.000 e 2.500 .000 pessoas, de uma população total de quase 16 milhões de habitantes. As remessas correspondem a aproximadamente 10,4\% do Produto Interno Bruto (PIB) do Senegal, segundo o Banco Mundial, sendo que cerca de $82 \%$ das remessas enviadas ao país são oriundas dos países europeus e apenas $6,6 \%$ de países americanos. O Haiti é o país do Caribe que mais recebe remessas. Em 2015 estas correspondiam a 25,32\% do PIB do país, que se estima tem um terço de sua população vivendo na diáspora.

Raros foram os migrantes entrevistados que não enviam semanal ou mensalmente uma importante quantia de seus rendimentos para familiares ou até mesmo para vizinhos, conhecidos, obras de caridade e trabalho social ou para financiar outros projetos migratórios. Quando, por causa de uma situação desfavorável como a falta de trabalho, atraso, não pagamento do salário, ou algum imprevisto, as remessas são suspensas ou interrompidas, as consequências podem ser bastante incertas e perigosas. Este foi o caso dramático de Mirele, que veio sozinha para o Brasil de forma indocumentada, o que significa que passou por diversos lugares e em condições bastante precárias (República Dominicana, Panamá, Equador, Peru) antes de chegar no Acre, de onde foi recrutada por uma empresa de Cascavel no Paraná, juntamente com outra mulher e mais de 50 homens, todos haitianos. Segundo seu depoimento, ela foi obrigada a se casar pois a empresa queria alugar casas e dispor as mulheres juntamente com os homens, situação que resultou em muita violência doméstica, pois o marido que a empresa escolhera além de trancá-la em casa batia nela todos os dias. Sua trajetória é extremamente comovente e ilustrativa das dificuldades pelas quais podem passar as mulheres migrantes quando se deslocam sozinhas. Ela havia deixado sua única filha, na época com apenas 1 ano, aos cuidados de uma amiga na República Dominicana e enviava mensalmente cerca de 
metade do salário que recebia trabalhando no setor de limpeza em um shopping. Entretanto, tendo se agravado uma doença antiga, seu ventre inchou e ela foi demitida sem justa causa porque a empresa suspeitou que estivesse grávida, vendo assim esvaírem-se suas economias. As remessas enviadas para sua amiga foram então se reduzindo até cessarem e, a partir disso, ela passou a ouvir ameaças à vida de sua filha, então com 6 anos de idade.

Outras mulheres, como muitos homens, resolveram migrar para construir novos horizontes imaginativos, projetando para si uma nova possibilidade de vida. Este foi o caso de Judith, que era casada no Haiti e tinha três filhos. Entretanto seu marido tinha, além dela, mais nove mulheres, e toda vez que ela reclamava da situação ele a espancava. Vir para o Brasil, ainda que sem qualquer certeza, representou um recomeço e atualmente ela está noiva de outro homem, também haitiano.

É possível perceber que apesar dos deslocamentos humanos não constituírem um fenômeno recente, apresentam-se em nova intensidade e com novos perfis. No que se refere ao mercado de trabalho, entre 2010 e 2015 o número de trabalhadores imigrantes cresceu $131 \%$ em todo o país. Apesar disso, como apontado por Handerson e Joseph (2015), é comum um sentimento de frustração de muitas mulheres haitianas que teriam migrado para o Brasil e que, mesmo com formação superior, trabalham com faxina ou limpeza doméstica. Tal fato também foi constatado nas cidades da grande Florianópolis tanto nas entrevistas feitas com homens quanto com mulheres provenientes do Haiti que em sua maioria buscam inserção no mercado formal e encontram vagas majoritariamente nos setores de construção civil, cuidados e alimentação, sendo frequentes os relatos de jornadas excessivas e salários menores que os dos brasileiros nas mesmas posições laborais, mesmo para aqueles que já possuem curso superior completo. Esta situação muitas vezes impulsiona uma reemigração ou mudanças de carreira, através de trabalhos, estudos ou de alternativas individuais ou coletivas que apontam para projetos artísticos ou informais, geralmente associados a identidades negras ou africanas. 
As migrações, para além destas precariedades, transformam a realidade local na medida em que reivindicam direitos, pois como Hommi Bhabha afirmou "os migrantes, os refugiados e os nômades não se limitam a circular. Necessitam também estabelecer-se, solicitar asilo ou nacionalidade, exigir acesso à moradia e à educação, fazer valer seus direitos econômicos e culturais e procurar para si o estatuto de cidadãos" (BHABHA, 2013, p. 26, tradução livre). Deste modo, problemas sociais de longa data como desemprego, exploração no setor de trabalho, condições de trabalho análogas à escravidão, falta de oferta de saúde, educação e segurança, são ampliados no confronto com o racismo, o preconceito e a intolerância religiosa, entre outros.

As migrações, neste sentido, são reveladoras na medida em que iluminam as maneiras como as sociedades modernas e contemporâneas construíram e constroem valores e fronteiras físicas e simbólicas, sobre resíduos históricos do colonialismo, do imperialismo, do neo-colonialismo e do capitalismo. De acordo com Stuart Hall, através de uma perspectiva transcultural e dialógica é possível compreender tanto "como o colonizado produz o colonizador quanto vice-versa" (HALL, 2009, p. 31). Deste modo, as transformações desencadeadas e demandadas pelas situações de refúgio e migração, em busca de visibilidade e direitos sociais, incluindo o direito de migrar como proposto na Declaração Universal dos Direitos Humanos, apontam para a possibilidade e necessidade de transformação da ordem hegemônica estabelecida.

Dos imigrantes haitianos que ingressaram no Brasil até 2014, cerca de 59,2\% concentravam-se na região Sul, sendo Santa Catarina o principal destino. Entre os senegaleses, ainda existem dificuldades de precisar estatisticamente os dados, mas em termos gerais, destinaram-se inicialmente, majoritariamente para os estados do Rio Grande do Sul e São Paulo. Entretanto, através de suas narrativas e trajetórias, fica evidente sua grande mobilidade interna, sendo frequente que já tenham morado em pelo menos três ou mais cidades dentro do Brasil, além de apresentarem um fluxo migratório que pode ser compreendido como sazonal, adaptando-se às estações do ano, às feiras, às oportunidades de emprego, negócios, comércio e outros fatores. A população senegalesa presente no Estado, estimada em aproximadamente duzentas pessoas, estabeleceu-se principalmente na capital, que proporciona maior mobilidade para viajar, 
além de muitos turistas durante a temporada de verão, uma vez que suas principais atividades econômicas estão relacionadas ao comércio. Segundo pudemos constatar, a maior parte dos homens já passou pela experiência do trabalho formal, seja em Santa Catarina, seja em outros Estados e em função de exploração, preconceito e baixos salários, optou pela atividade comercial de venda de mercadorias como roupas e eletrônicos, e apesar dos discursos midiáticos e do poder público que afirmam o contrário, reivindicam sua legalização e estabelecimento comercial formal. Alguns ainda começam a empreender e participar de feiras gastronômicas e de vestuário, acionando e performando pertencimentos étnicos relacionados à cultura e arte africana de modo geral.

Estas populações apresentam uma importante articulação comunitária expressa, entre outros, através de associações organizadas para a defesa de seus interesses e direitos. $\mathrm{Na}$ região é possível acompanhar este movimento que procura tornar visíveis suas reivindicações, sua cultura, fortalecer seu pertencimento étnico, disponibilizar oficinas e atividades culturais, entre outras importantes ações, através de grupos formais ou informais, com atuação provisória ou permanente.

\section{Poéticas e políticas do migrar}

Agier associa o recente interesse da antropologia das fronteiras, das mobilidades e da migração à mundialização humana e a uma nova condição cosmopolita (AGIER, 2016, p.9). Sua análise, baseada em pesquisas feitas ao longo quinze anos com pessoas em deslocamento, refugiadas e migrantes em diferentes partes do mundo, entretanto, constata que a mundialização, ao contrário das melhores perspectivas do final do século $X X$, tem tido por efeito a multiplicação de fronteiras, muitas vezes endurecidas por muros, o aumento das especificidades nas regulamentações regionais ou nacionais, e a distinção de categorias jurídicas de pessoas cada vez mais desiguais do ponto de vista dos direitos. Toda esta lógica burocrática e securitária, calcada no 'pânico social' (BAUMAN, 2016) tem contribuído para tornar a precariedade das migrações permanente e ordinária, estabelecendo performances excludentes de alteridade. Com argumento que 
propõe pensarmos os caminhos divergentes, Butler considera que a "universalização só tem chance de se renovar dentro de um projeto radicalmente democrático quando essas [suas próprias] normas são desmontadas" (BUTLER, 2017, p. 32).

A reflexão que apresentamos se baseia nas múltiplas maneiras pelas quais imigrantes e refugiados - designados como migrantes, conforme propõe Agier (2016) - se fazem presentes coetânea e simultaneamente nos mais diversos contextos, bem como sobre a positividade do fenômeno das migrações. Este termo, como propõe o autor, engloba as imigrações e as situações de refúgio e solicitação de refúgio, através da adoção de uma posição descentrada e crítica em relação aos enunciados administrativos, midiáticos ou públicos, que são categorias sempre em defasagem em relação à complexidade social. Segundo o autor a palavra migrante é um termo descritivo, neutro e genérico, referindose a pessoas em deslocamento, sem prejulgar de onde elas vêm ou para onde vão, ao passo que refugiados é uma categoria histórica e, como tal, sujeita a reelaborações conforme o contexto, além de compreender uma definição jurídica e institucional ${ }^{14}$. Entretanto, o acolhimento e tratamento às populações migrantes no Brasil é repleto de ambivalências e atravessamentos, a maior parte deles confluindo para um descompasso entre as leis e as experiências, quase sempre repletas de precariedades, incertezas e violências. Segundo Ângela Facundo (2017) a partir do momento da adoção da lei de refúgio de 199715, considerada avançada pelo Alto Comissariado das Nações Unidas

\footnotetext{
${ }^{14} \mathrm{O}$ estatuto do refugiado é definido por um ambiente internacional e histórico que evolui com seu contexto. Por esta razão Agier defende uma posição nominalista, através da qual são refugiados aqueles designados como tais pelas instituições habilitadas a fazê-lo, a HCR, a OFPRA (Office français pour la protection des réfugiés et apatrides) na França, CONARE no Brasil, etc. Isso porque muitos dos que são genericamente chamados de 'refugiados' não tem hoje o estatuto nem os direitos relacionados, sendo na maior parte das vezes solicitantes de refúgio ou imigrantes. Segundo a ONU - através da Convenção de Refugiados de 28 de julho de 1951 que entrou em vigor a 21 de abril de 1954 com a criação do Alto Comissariado das Nações Unidas para Refugiados (ACNUR) e em seguida pelo "Protocolo de 1967", ampliado pela Convenção que Regula os Aspectos Específicos dos Problemas dos Refugiados na África, adotado pela Assembleia dos Chefes de Estado e de Governo da Organização da Unidade Africana em 10 de setembro de 1969 - refugiado é "qualquer pessoa que, devido a uma agressão, ocupação externa, dominação estrangeira ou a acontecimentos que perturbem gravemente a ordem pública numa parte ou na totalidade do seu país de origem ou do país de que tem nacionalidade, seja obrigada a deixar o seu lugar de residência habitual para procurar refúgio em outro lugar fora do seu país de origem ou de nacionalidade" (p. 8).

15 Lei no 9.474 de 22 de julho de 1997. Antes disso o Brasil havia ratificado em 1960 a Convenção de Genebra de 1951, e em abril de 1972, aderido ao Protocolo de 1967 relativo à proteção dos refugiados sem restrições temporais. Além destas, a declaração de Cartagena de 1984, foi um marco importante pois
} 
para os Refugiados (ACNUR), a legislação brasileira e consequentemente, seus representantes políticos, vêm sendo reiteradamente elogiados no que se refere à disposição de acolher refugiados. A este discurso soma-se uma visão parcial sobre o passado brasileiro de acolhimento a imigrantes, que deixa, entretanto, de iluminar a seletividade implícita em relação à abertura do país para pessoas não brancas. Desta maneira o presente e o passado, ou ficções parciais sobre ambos, articulam um discurso que pretende compreender o Brasil como uma nação acolhedora para todos, quando de fato este acolhimento, quando existe, é bastante seletivo e restrito.

Refletir sobre o fenômeno dos múltiplos trânsitos de pessoas, mercadorias, saberes e práticas em escala global na contemporaneidade, bem como sobre os ruídos provocados e evocados, pode caminhar na direção de uma maior interdependência política no sentido do intercâmbio de experiências, em que se reflita sobre simetrias ao invés de perpetuar práticas de dominação e desigualdades. Os novos fluxos migratórios inseremse em um movimento amplo e complexo, consequência das transformações sociais, econômicas, políticas e culturais que atravessam o mundo, aceleradas pela globalização, pela crise dos Estados-nação e da modernidade, pelo aumento das desigualdades e dos conflitos locais, dos efeitos da colonização, do imperialismo, do desenvolvimento do capitalismo, dos processos de racialização, bem como da circulação de informações e bens, e portanto não podem ser considerados isoladamente.

Em função de suas escolhas e das possibilidades que encontram e criam, os sujeitos migrantes haitianos e senegaleses constantemente refazem suas trajetórias migratórias, movendo-se em direção à maior qualidade de vida, oportunidades e direitos. Não é raro que mesmo depois de terem residência e trabalho estável, ou de a família já ter se juntado no novo contexto, resolvam partir novamente em busca de melhores condições, ou de possibilidades de estudos ou rendimentos maiores. Para os que ainda não encontraram emprego fixo ou mínimas condições de inserção social, maiores ainda são 
as aberturas para o novo, para novas migrações que sobrepõem camadas às suas experiências migratórias.

A expressão '(co)mover' enfatiza a "experiência física do movimento entre lugares" (THOMSON, 2002, p. 359) e evoca afetos, através dos sentidos do mover e do comover. Isto se deve ao fato de que planos e trajetórias dos sujeitos migrantes são, em geral, continuamente reelaborados, assim como os sentidos implicados nos processos migratórios e nas narrativas e performances que os acompanham, permanecendo em constante movimento ou movimentando-se com relativa facilidade, apesar das fronteiras reais e simbólicas. Estas materializam-se pela ausência de políticas públicas, pela dificuldade de validação de diplomas, pela baixa oferta de atividades profissionais disponíveis ou pela oferta de atividades de nível inferior ao pretendido, pelos baixos salários, pela exploração da mão de obra, além de discriminações de gênero, classe, raça, religião e nacionalidade de origem. Além disto, suas trajetórias são comoventes para os próprios sujeitos migrantes, para suas famílias e conhecidos nos países de origem e de acolhida, influenciando trajetórias na diáspora que deste modo é atualizada e ressignificada, criando efeitos transformadores que movem e comovem transnacionalmente.

Desta maneira as migrações, através de uma abordagem atenta às interseccionalidades, atuam como fenômenos (co)movedores, implicando migrantes e não-migrantes em um processo dialógico de liminaridade e transformação que articula poéticas e políticas através da compatibilização e fricção de múltiplas dimensões da vida social. Entre os diversos desafios que se colocam está a compreensão dos novos fluxos migratórios em seu potencial transformador, a partir de uma responsabilidade ética contra-hegemônica que toma os múltiplos deslocamentos de pessoas neste novo milênio como desencadeadores de necessárias transformações sociais. Assim, compreender e dialogar com a pluralidade, a diversidade e a heterogeneidade colabora para a construção de novas bases relacionais, e as migrações recentes têm muito a ensinar através dos múltiplos (co)movimentos que desencadeiam, transformando o mundo que compartilhamos, contribuindo para que precariedades, violências, racismos e essencialismos sejam gradualmente desconstruídos. 
Portanto as migrações são atravessadas por processos de racializações e racismos evocando os efeitos dos processos de colonização que segundo Aimé Cesaire (2010) correspondem à 'coisificação', assim como a civilização corresponde à proletarização e mistificação, à destruição de modos de vida e de vidas, humanas e não humanas, embasadas nos discursos cientificistas e eugênicos de fontes diversas. Entretanto não apenas os colonialismos saqueadores e imperialismos exploradores de outrora ou atualizados sob inúmeras formas podem ser responsabilizados pelas desigualdades sociais entre nações ou populações, mas as atuais invisibilizações, fronteiras, leis de segurança nacional, barreiras à imigração, confinamentos, contenções e gerações inteiras vivendo em campos de refugiados, como demonstra Agier (2016). Mobilidade e imobilidade são portanto políticas de estado que atuam sobre os sujeitos e seus corpos, visando controlar e separar migrantes 'desejáveis' daqueles considerados 'não desejáveis' pelos discursos do poder.

\section{Considerações finais}

O processo migratório coloca em relação passado e presente, assim como contextos de origem e de chegada, discursos de 'nós' e 'eles', articulando novos sentidos às experiências vividas e evocando devires, resistindo à invisibilidade e ao silêncio. Migrantes insistem em se deslocar pelos espaços, criando novas formas de existir, constituindo um movimento que além de político é poético, transformando contextos e relações. Permanecem conectados afetiva ou materialmente com pessoas situadas em diversos países, enviam remessas materiais, recebem informações e as fazem circular em suas comunidades diaspóricas e fora delas. Aprendem a se deslocar e a deslocar seus pontos de vista continuamente e desta forma nos deslocam.

Homi Bhabha (2013) faz um elogio ao nomadismo e à mestiçagem como práticas éticas que se contrapõem ao império e à fixação, seja a uma nação, a uma identidade ou a um povo. Na mesma perspectiva, para Paul Gilroy, a diáspora desafia toda forma de fascismo "com seus distintos mitos de renascimento nacional" ao "valorizar parentescos sub e supranacionais", permitindo assim "uma relação mais ambivalente com as nações e com 
o nacionalismo" (GILROY, 2017, p. 19), e propondo uma relação entre igualdade e diferenciação étnica: "um mesmo mutável" (p.29). Segundo este autor, os deslocamentos sobre o oceano Atlântico desde o início da escravidão colonial foram sempre, paradoxalmente, uma oportunidade para trocas e articulações políticas, linguísticas e culturais, possibilitando muitas vezes a organização e disseminação de levantes por justiça, de cunho abolicionista e anti-escravista. Ele argumenta que "os padrões fractais de troca e transformação cultural e política" (Gilroy, 2017, p. 58) proporcionados pelos múltiplos deslocamentos sobre o Atlântico negro desde o século XVI permitem perceber a criatividade transnacional deste nas artes, no pensamento, nas lutas por emancipação e defesa de direitos, extrapolando políticas de nacionalidade e etnicidade, relacionando afetos e resistências na construção de novas possibilidades. James Clifford (1997) também elaborou o conceito de "traveling cultures" que inclui práticas de viagens modernas mas também aponta para complexidades e diferenças dos modelos de recepção e assimilação das populações migrantes, interseccionadas por gênero e raça. O autor ilumina a agência dos deslocamentos e processos migratórios que não são meramente movidos pelos ventos políticos e econômicos, sugerindo atenção às histórias dos migrantes numa perspectiva anti-colonial. Neste sentido convém o derradeiro livro de Bauman, no qual ele afirma que os migrantes são mensageiros de más notícias, "nos lembrando de modo irritante, exasperante e horripilante a (incurável?) vulnerabilidade de nossa própria posição e a fragilidade endêmica deste nosso bem-estar que tanto nos custou alcançar" (BAUMAN, 2016, p.21). Eles vêm nos lembrar do grande fracasso dos empreendimentos coloniais que Augé definiu como "primeiro esboço de mundialização" (AUGÉ, 2012, p.11). Ainda segundo Clifford (1997), velhas e novas diásporas oferecem recursos para pós-colonialismos emergentes na medida em que subvertem fronteiras e distâncias físicas, conectando pessoas, afetos, políticas, poéticas, espaços e tempos.

Para além das precariedades e restrições de direitos, apontamos, portanto, para a positividade do fenômeno migratório, que através dos constantes deslocamentos e de modos de estar no mundo mais fluídos e menos estáveis, atua como desencadeador de novos paradigmas contra-hegemônicos. As migrações assumem, sob este viés, uma 
dimensão política e poética performada e experienciada cotidianamente, que se expande, criando efeitos transformadores que movem e (co)movem. Enfatizamos assim seu potencial de criar transformações sociais e descentrar relações historicamente assimétricas e desiguais, provocando uma reestruturação que possa ser 'boa para pensar' e proporcione maneiras de sustentar uma ética de coabitação. Segundo Butler (2017a), através da ética da coabitação nos comprometemos não apenas com pessoas próximas, ou pertencentes ao país em que vivemos ou nascemos - assim como tampouco aceitamos sermos meros consumidores de imagens de pessoas em deslocamento ou sofrimento e tampouco indiferentes - mas passamos a questionar o que nos faz próximos ou distantes das desigualdades e tragédias humanitárias de todos os tempos e lugares. Para a autora "a heterogeneidade da população de nosso planeta é uma condição irreversível da vida social e política" e "estamos [também] obrigados a preservar estas vidas e a pluralidade sem limites que constitui a população mundial" (BUTLER, 2017a, p. 115, tradução livre). A partir deste pensamento somos implicados eticamente e tornamo-nos responsáveis não apenas pela coabitação como princípio, mas por garantir as melhores condições para que esta possa existir, tanto em âmbito local quanto internacional. Também Hannah Arendt (2010) defende que nenhuma ação ou discurso são possíveis no isolamento, e que "toda reação se converte em reação em cadeia, e (...) todo processo é causa de novos processos (...) [e] a reação, além de ser uma resposta, é sempre uma nova ação que segue seu curso próprio e afeta os outros". Disto decorre que "o menor dos atos, nas circusntâncias mais limitadas, traz em si a semente da mesma ilimitabilidade, pois basta um ato e, às vezes, uma palavra para mudar todo um conjunto" (ARENDT, 2010, p.239). Uma ética de coabitação, portanto, nos torna mais conscientes das implicações fractais de atos e discursos tanto no tempo quanto no espaço.

Assim, as populações migrantes desencadeiam, através de seus múltiplos deslocamentos, movimentos de transformação social, estabelecendo possibilidades éticas de resistências à ordem e às fronteiras físicas e simbólicas estabelecidas, em âmbito político, econômico e social, questionando as heranças do colonialismo e dos processos de racialização ainda vigentes, impondo novas configurações desestabilizadoras. A partir das narrativas 
e performatividades de migrantes haitianos e senegaleses, evidencia-se a importância do deslocamento e do movimento como epistemologias de necessárias transformações do mundo.

As migrações, segundo esperamos ter demonstrado, atuam como construtoras de espelhos que refletem e transformam o real, informando que migrantes e não-migrantes estão irremediavelmente inseridos em um processo dialógico de liminaridade e transformação. Neste processo articulam-se poéticas e políticas, através da compatibilização e fricção entre as múltiplas dimensões da vida social, percebidas e atravessadas em suas pontes e fronteiras reais ou metafóricas.

\section{Referências}

AGIER, Michel. Distúrbios identitários em tempos de globalização. Mana. Estudos de Antropologia Social, vol. 7 (2): 7-33, 2001.

Antropologia da Cidade: lugares, situações, movimentos. São Paulo: Ed. Terceiro Nome, 2011.

Les Migrantes et Nous: Compreendre Babel. Paris: CNRS Éditions, 2016.

BAUMAN, Zygmunt. Globalização: as consequências humanas. Rio de Janeiro: Zahar, 1999.

BASHI, V. Globalized anti-blackness: Transnationalizing Western immigration law, policy, and practice. Ethnic and Racial Studies Vol. 27 No. 4 July, p. 584-606, 2004.

BUTLER, Judith. Dar cuenta de sí mismo. Violência ética y responsabilidade. Buenos Aires: Amorrortu, 2009. $\overline{2015}$.

Relatar a si mesmo: crítica da violência ética. Belo Horizonte: Autêntica Editora,

Vida precária: el poder del duelo y la violência. Buenos Aires: Paidós, 2009.

Caminhos divergentes: judaicidade e crítica do sionismo. São Paulo: Boitempo, 2017.

Cuerpos aliados y lucha política. Ciudad Autónoma de Buenos Aires: Paidós, 2017a. 
. Cuerpos que importan. Sobre los límites materiales y discursivos del "sexo». Buenos Aires: Paidós. 2002 [1993].

CLASTRES, Pierre. A sociedade contra o estado - pesquisas de antropologia política. São Paulo: Cosac Naify, 2003.

CLIFFORD, James. A experiência etnográfica: antropologia e literatura no século XX. Rio de Janeiro: Editora UFRJ, 2014.

CRAPANZANO, Vincent. 1991. Diálogo. Anuário Antropológico, Brasília, n.88, p. 59, 80, 1991.

. Horizontes imaginativos e o aquém e além. Revista de Antropologia, 48(1), 363384, 2005.

DOUGLAS, Mary. Pureza e perigo: ensaios sobre as noções de poluição e tabu. Lisboa, Edições 70, 1991.

FELDMAN-BIANCO, Bela. Reinventando a localidade: Globalização heterogênea, escala da cidade e a incorporação desigual de migrantes transnacionais. In: Horizontes Antropológicos, Porto Alegre, ano 15, n. 31, p. 19-50, jan/jun, 2009.

GREEN, Nancy. Mudando paradigmas em estudos de migração, de homens para mulheres para gênero. In: Diásporas, Mobilidades e Migrações. Ilha de Santa Catarina: Editora Mulheres, 2011.

GRUZINSKI, Serge. O pensamento mestiço. São Paulo: Companhia das Letras, 2001.

HALL, Stuart. Da diáspora: identidades e mediações culturais. Belo Horizonte: Ed. UFMG, 2003.

LEIRIS, Michel. Espelho da Tauromaquia. São Paulo: Cosac \& Naify Edições, 2001.

SAYAD, Abdelmalek. A imigração ou os paradoxos da alteridade. São Paulo: EDUSP, 1998.

SILVA, Tomaz Tadeu da. A produção social da identidade e da diferença. In: Identidade e diferença: a perspectiva dos estudos culturais. Petrópolis, RJ: Vozes, 2014.

TAUSSIG, Michael. Xamanismo, colonialismo e o homem selvagem: um estudo sobre o terror e a cura. Rio de Janeiro: Editora Paz e Terra, 1993.

THOMSON, A. Histórias (co) movedoras: História Oral e estudos de migração. Revista Brasileira de História. São Paulo, v. 22, no 44, pp. 341-364, 2002. 
Turner, Victor. Images and Reflections: Ritual, Drama, Carnival, Film and Spectacle in Cultural Performance. In The Anthropology of Performance. New York: PAJ Publications, 1987.

Turner, Victor. Dramas, Campos e Metáforas. Niterói, EDUFF, 2008.

O Processo Ritual: estrutura e antiestrutura. Petrópolis, RJ: Vozes, 2013.

SANSOT, Pierre. Les formes sensibles de la vie sociale. Presses Universitaires de France: Paris, 1986. 